\title{
Turning up the heat: heat stress induces markers of programmed cell death in Plasmodium falciparum in vitro
}

\author{
D Engelbrecht ${ }^{\star, 1}$ and TL Coetzer ${ }^{1,2}$
}

Malaria is characterised by cyclical febrile episodes that result from the rupture of mature schizont-infected erythrocytes releasing merozoites. In patients infected with Plasmodium falciparum, fever may reach peak temperatures as high as $41^{\circ} \mathrm{C}$. Febrile episodes typically have a deleterious effect on parasites and probably benefit the host by aiding parasite clearance; however, the parasite may also gain advantage from limiting its burden on the host and prolonging infection to ensure development and transmission of slow-maturing gametocytes. Programmed cell death (PCD) may provide the parasite with a mechanism of self-limitation, although the occurrence and phenotype of PCD in the erythrocytic stages remain controversial due to conflicting data. This study aimed to characterise the cell death phenotype of $P$. falciparum in response to in vitro heat stress. A variety of biochemical markers of PCD, including DNA fragmentation, mitochondrial dysregulation and phosphatidylserine externalisation, as well as morphological studies of Giemsa-stained thin smears and real-time microscopy were utilised to characterise the phenotype. Heat stress decreased $P$. falciparum growth and development in vitro. Late-stage parasites were more susceptible, although early stages were more affected than expected. Early-stage parasites exposed to $41{ }^{\circ} \mathrm{C}$ exhibited markers of an apoptosis-like PCD phenotype, including DNA fragmentation and mitochondrial depolarisation. Heat-stressed latestage parasites showed no significant DNA fragmentation or mitochondrial dysregulation; however, cytoplasmic vacuolisation was suggestive of an autophagy-like form of PCD. Our results therefore showed that biochemical and morphological markers of PCD varied with intra-erythrocytic parasite development and that $P$. falciparum exhibited facets of both apoptosis- and autophagy-like phenotypes after exposure to febrile temperatures, which may reflect a unique PCD phenotype.

Cell Death and Disease (2013) 4, e971; doi:10.1038/cddis.2013.505; published online 19 December 2013

Subject Category: Experimental Medicine

Malaria is characterised by acute cyclical febrile episodes that are triggered by the rupturing of mature schizontinfected erythrocytes releasing merozoites. ${ }^{1}$ In Plasmodium falciparum malaria, fever typically recurs every $48 \mathrm{~h},{ }^{2,3}$ coinciding with the parasite's erythrocytic life cycle, ${ }^{2}$ and may peak as high as $41^{\circ} \mathrm{C}$ for $2-6 \mathrm{~h}^{3}$ However, multiple asynchronous infections may lack periodicity ${ }^{3}$ and febrile episodes may therefore occur more frequently and last longer.

Elevated temperatures of $40^{\circ} \mathrm{C}$ for $6 \mathrm{~h}$ or more significantly inhibited $P$. falciparum growth in vitro, ${ }^{4-6}$ with greater than $95 \%$ parasite death after $48 \mathrm{~h} .{ }^{6}$ Exposure to $41{ }^{\circ} \mathrm{C}$ significantly decreased parasite survival after only $2 \mathrm{~h},{ }^{7}$ with parasite death noticed after as little as $30 \mathrm{~min}$ exposure. ${ }^{8}$ The late developmental stages of trophozoites and schizonts were more susceptible to hyperthermal damage, whereas the ring stages were more resistant, ${ }^{4-8}$ with exposures to $40^{\circ} \mathrm{C}$ causing synchronization towards the ring stage. ${ }^{4,8}$ Exposure to $41^{\circ} \mathrm{C}$ has been shown to also inhibit the growth of these early stages. ${ }^{7,8}$ Although febrile episodes are generally considered to benefit the host by suppressing parasite growth and assisting in clearance, ${ }^{5}$ parasites may also derive benefit from increased temperatures. In vitro studies have shown that $P$. falciparum growth rates and development were accelerated when parasites were exposed to $40^{\circ} \mathrm{C}$ for $2 \mathrm{~h}$, incubated at $37^{\circ} \mathrm{C}$ for $10 \mathrm{~h}$ and again exposed to $40{ }^{\circ} \mathrm{C}$ for $12-24 \mathrm{~h} .{ }^{9}$ The parasite life cycle was also accelerated after exposure to less severe temperatures of $38.5-39^{\circ} \mathrm{C} .{ }^{10}$ Incubation at $40{ }^{\circ} \mathrm{C}$ for $1-2 \mathrm{~h}$ enhanced the cytoadherence of mature $P$. falciparuminfected erythrocytes (pRBC) to CD36 and ICAM-1 receptors and also caused adherence of ring-stage parasites, which do not normally bind to these receptors. ${ }^{11}$ Febrile temperatures have also been shown to reduce the deformability of $\mathrm{pRBC}$, which may aid in sequestration, ${ }^{12}$ as well inducing phosphatidylserine (PS) externalisation in pRBC. ${ }^{10}$

\footnotetext{
${ }^{1}$ Wits Research Institute for Malaria, Department of Molecular Medicine and Haematology, Faculty of Health Sciences, School of Pathology, University of the Witwatersrand, Johannesburg, South Africa and ${ }^{2}$ National Health Laboratory Service, Johannesburg, South Africa

${ }^{*}$ Corresponding author: D Engelbrecht, Wits Research Institute for Malaria, Department of Molecular Medicine and Haematology, Faculty of Health Sciences, School of Pathology, University of the Witwatersrand, Room 7Q06 Wits Medical School, 7 York Road, Parktown, Johannesburg, Gauteng 2193, South Africa. Tel: +27 11717 2418; Fax: +27 11717 2395; E-mail: DewaldtEngelbrecht@gmail.com

Keywords: Plasmodium falciparum; programmed cell death; febrile temperature; heat stress

Abbreviations: pRBC, Plasmodium falciparum-infected red blood cell; $P S$, phosphatidylserine; $\triangle \Psi$ m, mitochondrial transmembrane potential; PCD, programmed cell death; TUNEL, terminal deoxynucleotidyl transferase dUTP nick end labelling; HE, hydroethidine; ROS, reactive oxygen species; Atg, autophagy-related; TO, thiazole orange; $\mathrm{DiOC}_{6}(3), 3,3^{\prime}$-dihexyloxacarbocyanine iodide; CCCP, carbonyl cyanide m-chlorophenylhydrazone; MCM, malaria culture medium; PBS, phosphate-buffered saline; PI, propidium iodide

Received 06.9.13; revised 14.11.13; accepted 14.11.13; Edited by A Stephanou
} 
Heat shock triggers activation of the intrinsic apoptosis pathway in metazoans, resulting in permeabilisation of the mitochondrial outer membrane with concurrent depolarisation of the mitochondrial transmembrane potential $(\Delta \Psi \mathrm{m})$ and the initiation of an enzyme cascade that ends in DNA fragmentation. ${ }^{13} \mathrm{~A}$ growing body of evidence suggests that $P$. falciparum may undergo programmed cell death (PCD), although some conflicting results have suggested a range of cell death phenotypes, including apoptosis, autophagy-like cell death, necrosis or simply undetermined. Phenotypes may also not be exclusive and overlap may occur. ${ }^{14}$ According to the best of our knowledge, data regarding the possible induction of PCD by heat stress are limited to two studies, which have offered conflicting conclusions, with an apoptosis-like form of PCD suggested on the one hand ${ }^{7}$ and the other suggesting that cell death more closely resembled secondary necrosis, although some form of PCD was not ruled out. ${ }^{6}$

We present a comprehensive in vitro study that utilised a variety of biochemical and morphological markers of cell death, as well as heat stress of different duration and intensity, to provide extensive characterisation of the response of $P$. falciparum to conditions similar to febrile episodes experienced during malaria. $P$. falciparum exhibited markers of PCD, including DNA fragmentation, mitochondrial dysregulation, PS externalisation and cytoplasmic vacuolisation. However, early and late intra-erythrocytic stages differed in their response to heat stress and exhibited different phenotypes, which may represent different facets of a single PCD mechanism unique to $P$. falciparum. Febrile temperatures may induce self-limitation of parasite populations through PCD in vivo to the benefit of both the host and parasite. Elucidation of a PCD mechanism distinct from metazoans in $P$. falciparum may yield novel drug targets to be exploited in manipulating parasite fate.

\section{Results}

Heat stress inhibits $\boldsymbol{P}$. falciparum growth and development. Parasitised cultures were exposed to heat stress to mimic either the extended fever periods experienced during prolonged malaria $\left(40^{\circ} \mathrm{C}\right.$ for 6 or $24 \mathrm{~h}$, Figure 1$)$ or the occasional high peaks of fever paroxysms $\left(41^{\circ} \mathrm{C}\right.$ for $2 \mathrm{~h}$, Figure 2), and the response of the parasites was characterised with biochemical markers of PCD (Table 1). We observed time-dependant inhibition of growth and development by exposure to $40^{\circ} \mathrm{C}$, with late-stage parasites more severely affected. After $6 \mathrm{~h}$ exposure, an apparent delay was noted in the development of ring-stage parasites to late stages between 24 and $48 \mathrm{~h}$ (Figure 1). Ring-stage parasites became more vulnerable to heat stress at $41^{\circ} \mathrm{C}$ and were more affected than previously thought: $\sim 75 \%$ of early-stage parasites exposed to $41^{\circ} \mathrm{C}$ for $2 \mathrm{~h}$ (Figure 2) failed to develop, compared with a $25 \%$ reduction in parasite survival previously shown under the same conditions. ${ }^{7}$ The effect of heat stress on late-stage parasites also became more pronounced at $41^{\circ} \mathrm{C}$, with very few parasites observed $24 \mathrm{~h}$ after exposure, in comparison with control parasites maintained at $37^{\circ} \mathrm{C}$, which replicated to form new rings (Figure 2).
Heat stress induces markers of PCD in $P$. falciparum. $P$. falciparum exposed to heat stress exhibited a number of markers of PCD, including DNA fragmentation, mitochondrial dysregulation, PS externalisation and cytoplasmic vacuolisation, which varied with the developmental stage and in some instances with the temperature and duration of heat stress (see Table 1 for summary).

DNA fragmentation, quantified by the flow cytometric TUNEL (terminal deoxynucleotidyl transferase dUTP nick end labelling) assay, was observed in mixed-stage cultures exposed to $40^{\circ} \mathrm{C}$ for $24 \mathrm{~h}$ (Figures 3aii and bii) but not for $6 \mathrm{~h}$ (Figures 3ai and bi). Therefore, $24 \mathrm{~h}$ was chosen for further experiments involving exposure to $40^{\circ} \mathrm{C}$. DNA fragmentation was also observed in synchronised ring-stage parasites exposed to $41^{\circ} \mathrm{C}$ for $2 \mathrm{~h}$ (Figures 3aiii and biii). Surprisingly, late-stage parasites exposed to the same stress exhibited insignificant DNA fragmentation (Figures 3aiv and biv) at $24 \mathrm{~h}$, despite a significant decrease in parasitaemia (Figure 2). Therefore, exposure to $41^{\circ} \mathrm{C}$ may have caused the formation of nonviable merozoites that failed to invade new cells, whereas surviving parasites likely sustained little or no damage.

Mitochondrial depolarisation, generally considered to be characteristic of apoptosis, ${ }^{15-20}$ was observed immediately following heat stress in early-stage parasites exposed to $40{ }^{\circ} \mathrm{C}$ for $24 \mathrm{~h}$ (Figures $4 \mathrm{ai}$ and bi), although it was not noted the following day (Figures 4aii and bii). Early-stage parasites exposed to $41^{\circ} \mathrm{C}$ for $2 \mathrm{~h}$ exhibited slight mitochondrial depolarisation immediately after heat stress (Figures 4aiii and biii) that was significant the next day (Figures 4aiv and biv). Many of the ring-stage parasites exposed to $40{ }^{\circ} \mathrm{C}$ developed further (Figure 1), whereas $\sim 75 \%$ of ring-stage parasites exposed to $41^{\circ} \mathrm{C}$ did not (Figure 2aiii). Surprisingly, late-stage parasites exposed to $40^{\circ} \mathrm{C}$ for $24 \mathrm{~h}$ exhibited mitochondrial hyperpolarisation (Figures 5ai and bi), that was less prominent the following day (Figures 5aii and bii). No change was observed in the $\Delta \Psi \mathrm{m}$ of late-stage parasites exposed to $41^{\circ} \mathrm{C}$ (Figures 5aiii-iv and biii-iv). In accordance with previous studies, ${ }^{10}$ increased PS externalisation was observed in late-stage pRBC exposed to $41^{\circ} \mathrm{C}$ a day after heat stress was withdrawn (Figures 6avi and bvi). No increase was noted in synchronised ring-stage $\mathrm{pRBC}$ immediately after exposure to $41^{\circ} \mathrm{C}$ for $2 \mathrm{~h}$ (Figures 6aiii and biii), with an apparent decrease noted at $48 \mathrm{~h}$ (Figures 6aiv and biv); however, when comparing the heat-stressed culture at both time points (iii and iv), no change was apparent. PS externalisation was also noted in mixed cultures immediately after $24 \mathrm{~h}$ exposure to $40^{\circ} \mathrm{C}$ (Figures 6ai and bi).

Most late-stage parasites exposed to $41^{\circ} \mathrm{C}$ for $2 \mathrm{~h}$ were observed outside erythrocytes on Giemsa-stained thin smears at $24 \mathrm{~h}$, whereas many intracellular parasites exhibited jagged borders and prominent vacuoles within the cytoplasm (Figure 7). Real-time microscopy showed that many of the remaining intracellular parasites, despite not replicating to new ring stages, presented with continued rapid movement (Supplementary Videos) similar to that observed in $37^{\circ} \mathrm{C}$ controls and considered characteristic of healthy parasites. ${ }^{21}$ A clear recovery, evidenced by increased parasitaemia (Supplementary Figure 1), was noted 5 days after heat stress. Ring-stage parasites exposed to the same 
a

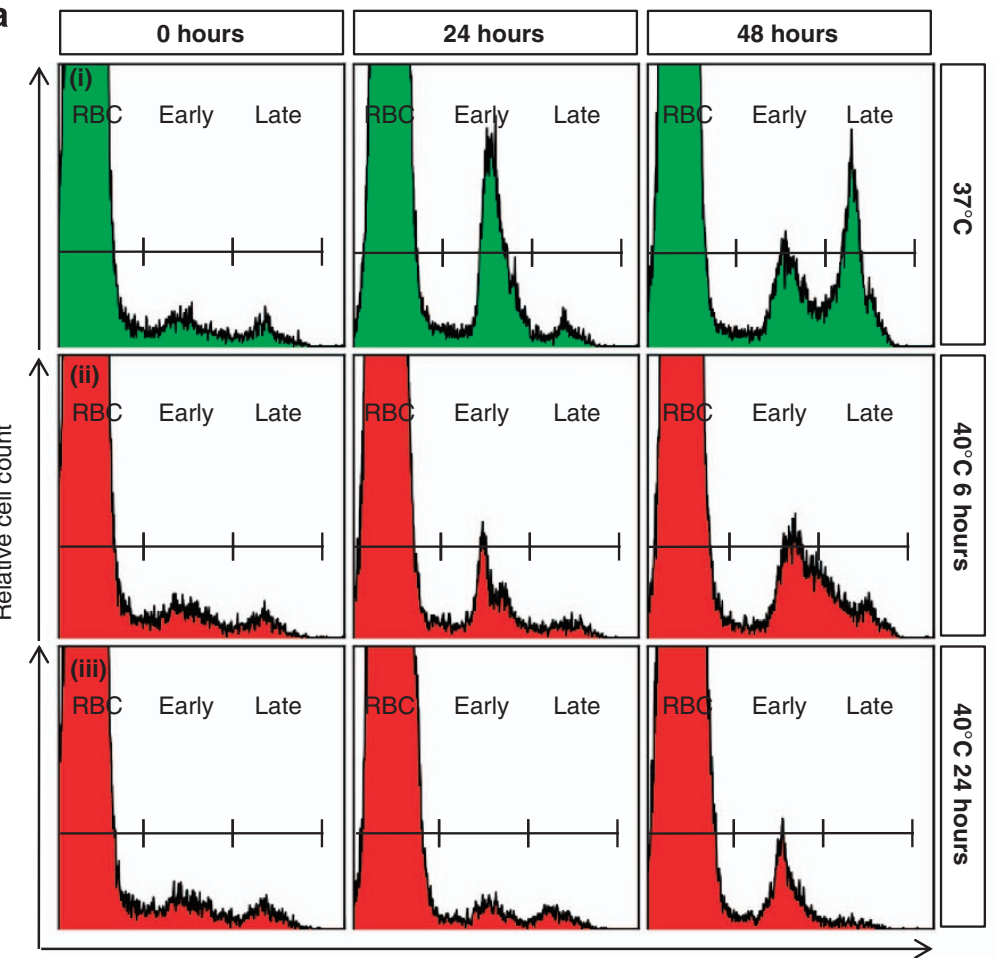

FL 1 Fluorescence: Thiazole orange (log)

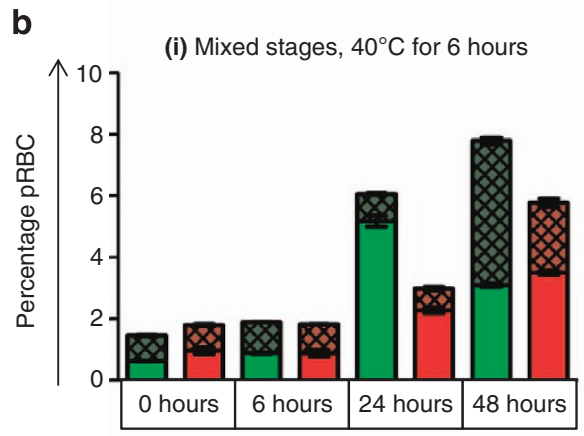

(ii) Mixed stages, $40^{\circ} \mathrm{C}$ for 24 hours

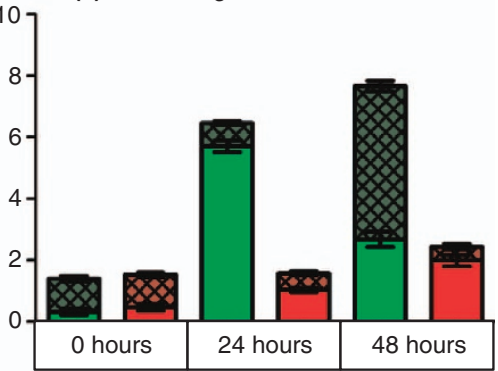

Time interval

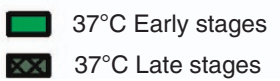

$\square 40^{\circ} \mathrm{C}$ Early stages

$40^{\circ} \mathrm{C}$ Late stages

Figure 1 Exposure to $40^{\circ} \mathrm{C}$ inhibited growth and development in mixed-stage $P$. falciparum in an exposure-dependant manner. Compared with control parasites kept at $37^{\circ} \mathrm{C}$ (ai), cultures exposed to $40^{\circ} \mathrm{C}$ for 6 or $24 \mathrm{~h}$ (aii and iii, respectively) showed an exposure-dependant inhibition in the formation of new ring-stage parasites (Early) from late-stage parasites (Late) at $24 \mathrm{~h}$, with a correspondingly smaller late-stage population at $48 \mathrm{~h}$ (b). Late-stage parasites were more affected by heat stress. However, a delay in the development of ring-stage parasites to late stages was apparent between 24 and $48 \mathrm{~h}$ after $6 \mathrm{~h}$ exposure, which resulted in a broad, indiscrete peak at $48 \mathrm{~h}$ (aii), indicating a population of intermediate development. Furthermore, after $24 \mathrm{~h}$ exposure, few early-stage parasites at $24 \mathrm{~h}$ appeared to progress to late stages at $48 \mathrm{~h}$ (aiii and bii). Raw flow cytometry histograms (a) and stacked bar graphs (b) are shown. Stacked bar graphs show changes in parasitaemia (total bar height) and relative composition of the parasite population with respect to early- and late-stage parasites. For (bi) $n=2$, for (bii) $n=6$ at $24 \mathrm{~h}$ and $n=4$ at $48 \mathrm{~h}$. Data points represent arithmetic mean \pm S.E.M. Heat stress was applied at $0 \mathrm{~h}$

stress conditions also showed abnormal morphology on Giemsa-stained thin smears (Figure 7), although morphologically normal parasites were also observed.

\section{Discussion}

In vitro $P$. falciparum exhibited various biochemical markers of PCD, including DNA fragmentation, mitochondrial dysregulation and PS externalisation, as well as some abnormal morphological features including cytoplasmic vacuolisation, in response to heat stress. Different stages of the parasite life cycle exhibited a different combination of PCD markers, which also varied depending on the temperature and the duration of the heat stress.

Heat stress in P. falciparum: a single degree makes a difference. Several previous studies have shown that febrile temperatures inhibit $P$. falciparum growth in vitro ${ }^{4,5,8,22}$ and 


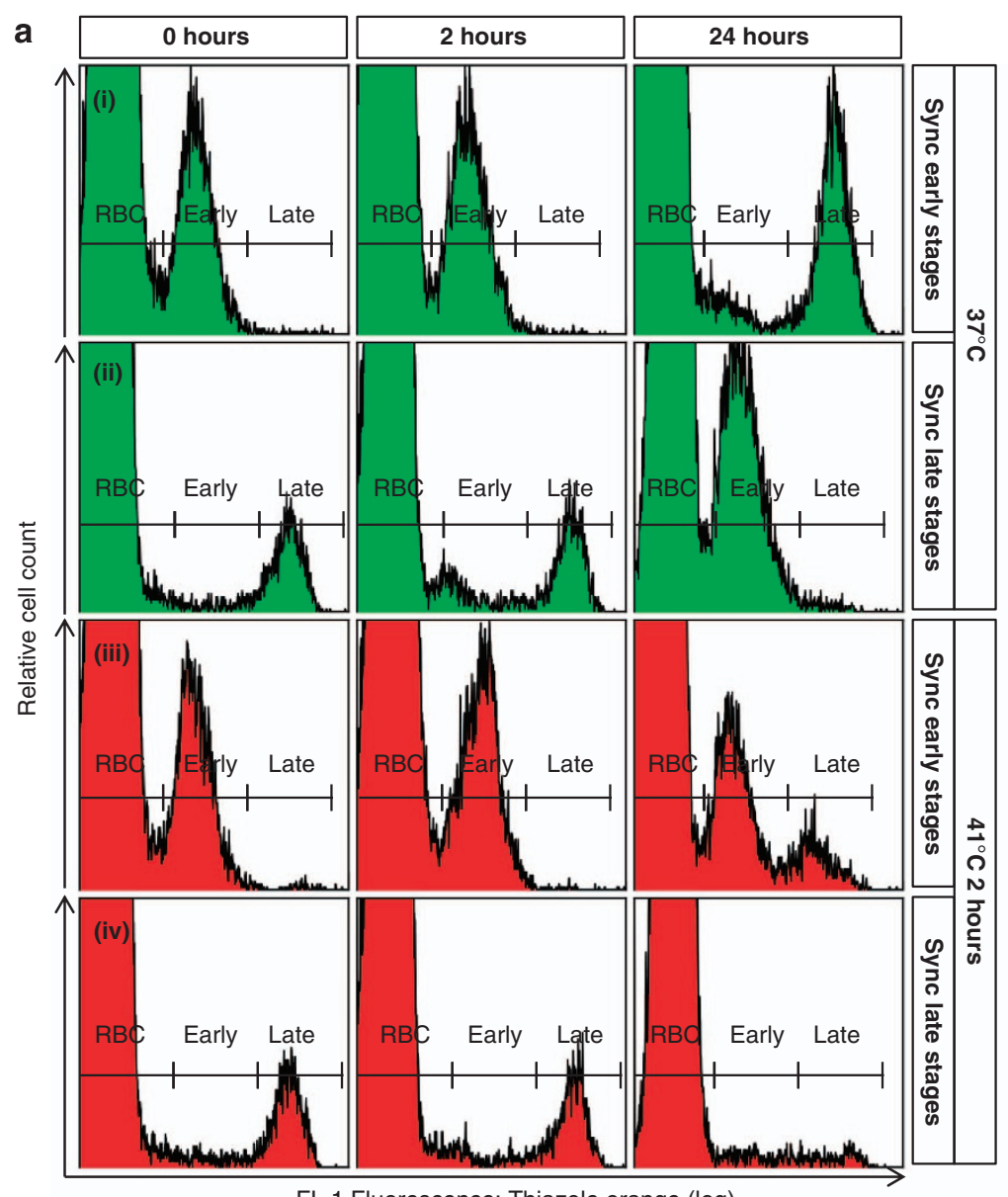

FL 1 Fluorescence: Thiazole orange (log)

b

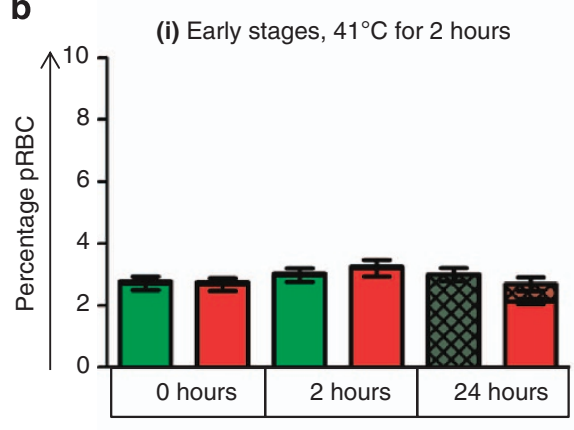

(ii) Late stages, $41^{\circ} \mathrm{C}$ for 2 hours

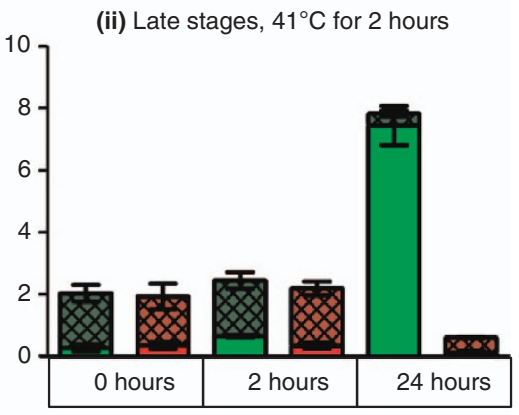

Time interval

$\square 7^{\circ} \mathrm{C}$ Early stages

$37^{\circ} \mathrm{C}$ Late stages

$41^{\circ} \mathrm{C}$ Early stages

$41^{\circ} \mathrm{C}$ Late stages

Figure 2 Exposure to $41^{\circ} \mathrm{C}$ for $2 \mathrm{~h}$ inhibited replication and development of both early- and late-stage synchronised $P$. falciparum. Representative flow cytometry histograms (a) showed the progression of early (i) and late (ii) stage parasites kept at $37^{\circ} \mathrm{C}$, in comparison with early (iii) and late (iv) stage parasites exposed to $41^{\circ} \mathrm{C}$ for $2 \mathrm{~h}$. Time intervals are indicated on top, whereas synchronisation and treatment conditions are indicated on the right. (b) Stacked bar graphs show changes in parasitaemia (total bar height) and relative composition of the parasite population with respect to early- and late-stage parasites. A small portion of ring stage (Early) parasites exposed to $41^{\circ} \mathrm{C}$ developed to late stages (Late), while most remained as ring-stage parasites. Late stages exposed to $41{ }^{\circ} \mathrm{C}$ failed to produce viable merozoites to infect erythrocytes and virtually no parasites were detected at $24 \mathrm{~h}$, compared with $37^{\circ} \mathrm{C}$ control parasites, which showed a large new ring population. Data points represent arithmetic mean \pm S.E.M. ( $n=4$ for bi and $n=5$ for bii). Heat stress was applied at $0 \mathrm{~h}$

have noted that the effect varies with temperature. ${ }^{5,8}$ However, only two studies have investigated the appearance of PCD markers in response to heat stress and those studies utilised different strains, cell death markers and heat stress conditions, and have offered conflicting conclusions. ${ }^{6,7}$ We utilised heat stress conditions similar to both previous studies and scored a variety of biochemical and morphological markers to characterise the cell death phenotype in 
Table 1 Summary of biochemical markers of cell death observed in $P$. falciparum after exposure to increased temperatures

\begin{tabular}{|c|c|c|c|c|}
\hline \multirow{3}{*}{$\begin{array}{l}\text { Parasite life stage } \\
\text { Exposure conditions } \\
\text { Time of measurements }\end{array}$} & \multicolumn{2}{|c|}{ Early stages at $0 \mathrm{~h}$} & \multicolumn{2}{|c|}{ Late stages at $0 \mathrm{~h}$} \\
\hline & $40^{\circ} \mathrm{C}$ for $24 \mathrm{~h}$ & $41^{\circ} \mathrm{C}$ for $2 \mathrm{~h}$ & & \\
\hline & $\begin{array}{l}\text { Immediately after heat } \\
\text { stress }\end{array}$ & $22 \mathrm{~h}$ after heat stress & $\begin{array}{l}\text { Immediately after heat } \\
\text { stress }\end{array}$ & $22 \mathrm{~h}$ after heat stress \\
\hline Growth and development & $\begin{array}{l}\text { Slight growth inhibition. } \\
\text { Progression to late stages } \\
\text { was similar to } 37^{\circ} \mathrm{C} \text { control } \\
\text { parasites (Figure 1) }\end{array}$ & $\begin{array}{l}\text { Inhibition of growth. A small } \\
\text { number developed to late } \\
\text { stages (Figure 2) }\end{array}$ & $\begin{array}{l}\text { Severe growth inhibition } \\
\text { with very few ring parasites } \\
\text { observed (Figure 1) }\end{array}$ & $\begin{array}{l}>95 \% \text { growth inhibition, with } \\
\text { no new ring-stage parasites } \\
\text { formed (Figure 2) }\end{array}$ \\
\hline DNA fragmentation & & Yes (Figure 3aiii) & * & Slight (Figure 3aiv) \\
\hline Mitochondrial & Depolarised (Figure 4bi) & Depolarised (Figure 4bii) & Hyperpolarised (Figure 5bi) & No change (Figure 5bii) \\
\hline PS externalisation & * & No (Figures $6 c$ and d) & * & Yes (Figure 6f) \\
\hline
\end{tabular}

Parasite life stages, incubation conditions and relevant figures for each result are indicated. Asterisks $\left({ }^{\star}\right)$ indicate no data, as effects were observed in mixed-stage cultures

a
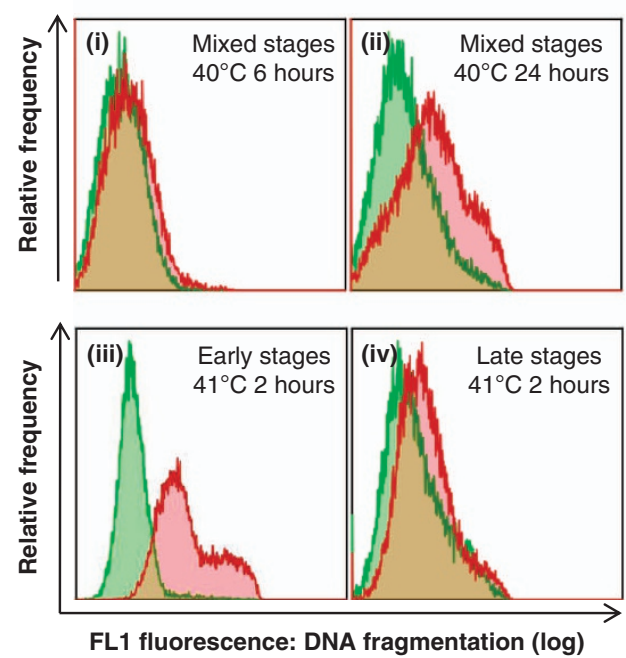

b

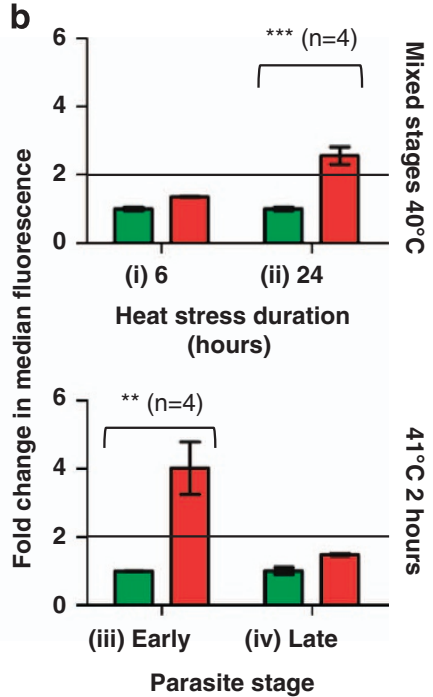

Figure 3 Heat stress induced DNA fragmentation in P. falciparum, as measured by the TUNEL assay. Control parasites, incubated at $37^{\circ} \mathrm{C}$, are indicated in green, whereas heat-stressed parasites are indicated in red. All samples were collected at $24 \mathrm{~h}$. TUNEL results indicated significant DNA fragmentation in mixed-stage parasites exposed to $40^{\circ} \mathrm{C}$ for $24 \mathrm{~h}$ and synchronised ring-stage parasites exposed to $41^{\circ} \mathrm{C}$ for $2 \mathrm{~h}$, with only slight fragmentation in synchronised late-stage parasites exposed to the same stress, compared with control parasites at identical time intervals. (a) Overlaid fluorescence histograms of the TUNEL assay indicate the FL1 (dUTP-FITC) fluorescence of isolated parasites from individual heat-stressed (red) or control (green) data sets. Fragmentation resulted in a higher fluorescence, indicated by a shift towards the right. Heat stress conditions are indicated in the top right corner of each overlay. Figure numbers (i-iv) match those of the bar graphs. (b) Bar graphs summarise TUNEL results for mixedstage parasites exposed to $40^{\circ} \mathrm{C}$ for 6 (i) and 24 (ii) hours, as well as synchronised early (iii) and late (iv) stage parasites exposed to $41^{\circ} \mathrm{C}$ for $2 \mathrm{~h}$. Changes in fragmentation are indicated as the mean change in median fluorescence for all samples. Differences of twofold or greater (indicated by a horizontal line on bar graphs) between heat-stressed and corresponding $37^{\circ} \mathrm{C}$ control parasites are considered indicative of fragmentation. Data points indicate the arithmetic mean of replicates \pm S.E.M. Comparisons between control and heat-stressed parasites showed $P$-values that are significant at $<0.01\left(^{* *}\right)$ or $\left.<0.001{ }^{(* *}\right)$

intra-erythrocytic $P$. falciparum after heat stress. An apoptosislike phenotype was previously suggested based on geneexpression studies in asynchronous parasites and DNA fragmentation detected in schizont-stage parasites by the in situ TUNEL assay, after exposure to $41^{\circ} \mathrm{C}$ for $2 \mathrm{~h} .{ }^{7}$ After the same exposure, our data showed no significant DNA fragmentation in late-stage parasites; however, we did observe DNA fragmentation in ring-stage parasites, which Oakley et al. ${ }^{7}$ did not consider. We also utilised flow cytometry to quantify the TUNEL assay, rather than fluorescence microscopy. ${ }^{7}$ After exposure to $40^{\circ} \mathrm{C}$ for various durations up to $48 \mathrm{~h}$, Porter et al. ${ }^{6}$ reported a lack of DNA fragmentation or caspase activation, mitochondrial depolarisation in late-stage parasites as well as food vacuole swelling and lysis. Although heat-induced PCD was not ruled out, it was suggested that the parasite cell death response more closely resembled secondary necrosis. ${ }^{6}$ In contrast, we observed significant DNA fragmentation in mixed-stage cultures after exposure to $40^{\circ} \mathrm{C}$ for $24 \mathrm{~h}$, quantified by the TUNEL assay, which is more sensitive than the agarose gels utilised previously. ${ }^{6}$ Furthermore, we surprisingly found mitochondrial hyperpolarisation in late-stage parasites, whereas only early-stage parasites showed depolarisation. It is worth noting that, although we utilised similar mitochondrial staining methods, we discriminated between early- and late-stage pRBC based on hydroethidine (HE) uptake, whereas Porter et al. ${ }^{6}$ used synchronised cultures. Our data showed that differences in heat stress conditions may at 

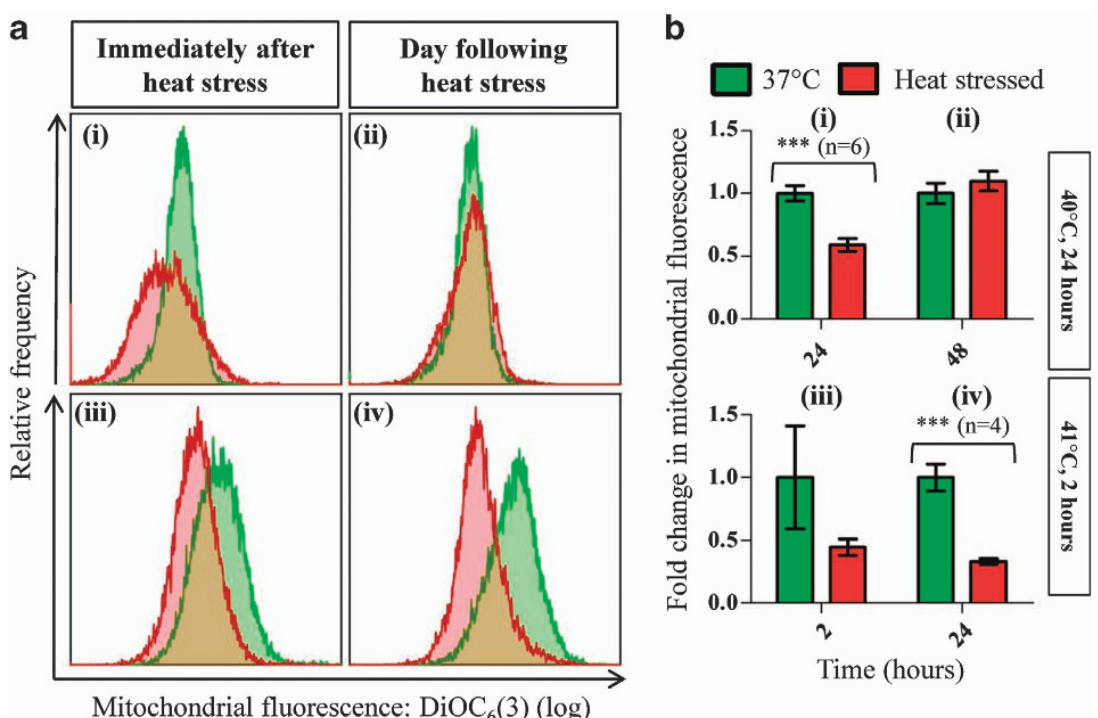

Figure 4 Heat stress induced mitochondrial depolarisation in early-stage parasites. Mitochondrial depolarisation was observed immediately following heat stress in earlystage parasites exposed to $40^{\circ} \mathrm{C}$ for $24 \mathrm{~h}$ (i), although it was not noted the following day (ii). Early-stage parasites exposed to $41^{\circ} \mathrm{C}$ for $2 \mathrm{~h}$ exhibited slight mitochondrial depolarisation immediately after heat stress (iii) that was significant the next day (iv). (a) Overlays of $\mathrm{DiOC}_{6}(3)$ fluorescence histograms show representative merged data sets of at least two replicates for each time point and condition as an individual peak. A decrease in the median fluorescence of a population is indicated by a shift to the left (depolarisation). Fluorescence values were taken as the median fluorescence of individual populations. (b) Bar graphs indicate the arithmetic mean of replicates \pm S.E.M. Comparisons between control and heat-stressed parasites showed $P$-values that are significant at $\left.<0.001{ }^{* * *}\right)$. Heat stress conditions are indicated on the right
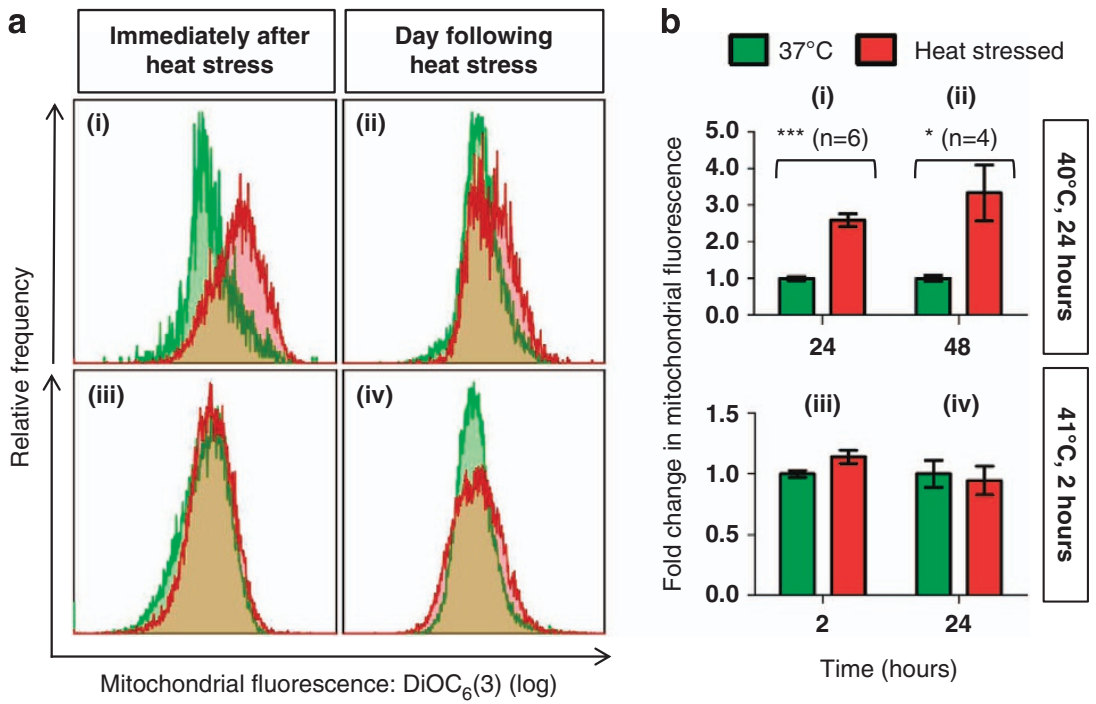

Figure 5 Heat stress-induced mitochondrial hyperpolarisation in late-stage parasites exposed to $40^{\circ} \mathrm{C}$ for $24 \mathrm{~h}$. Late-stage parasites exposed to $40^{\circ} \mathrm{C}$ for $24 \mathrm{~h}$ showed mitochondrial hyperpolarisation after heat stress (i) and the following day (ii), whereas late-stage parasites exposed to $41^{\circ} \mathrm{C}$ for $2 \mathrm{~h}$ showed practically no change in mitochondrial polarisation (iii and iv). (a) Overlays of $\mathrm{DiOC}_{6}$ (3) fluorescence histograms show representative merged data sets of at least two replicates for each time point and condition as an individual peak. An increase in the median fluorescence of a population is indicated by a shift to the right (hyperpolarisation). Fluorescence values were taken as the median fluorescence of individual populations. (b) Bar graphs indicate the arithmetic mean of replicates \pm S.E.M. Comparisons between control and heat-stressed parasites showed $P$-values that are significant at $<0.05\left({ }^{*}\right)$ or $<0.001\left({ }^{* *}\right)$. Heat stress conditions are indicated on the right

least partly explain the conflicting conclusions of previous studies. ${ }^{6,7}$ More significantly, however, our data suggested that the PCD phenotype depends on the intra-erythrocytic developmental stage. Early-stage parasites showed biochemical markers of PCD that were reminiscent of an apoptosis-like form of PCD. The phenotype observed in late-stage parasites, which exhibited a different combination of biochemical markers as well as cytoplasmic vacuolisation and continued survival after heat stress despite no replication, appeared similar to autophagy-like cell death.

Give and take: the potential mutual benefits of fever in malaria. Central to this study was the following question: who benefits most from fever during malarial illness - parasite or 


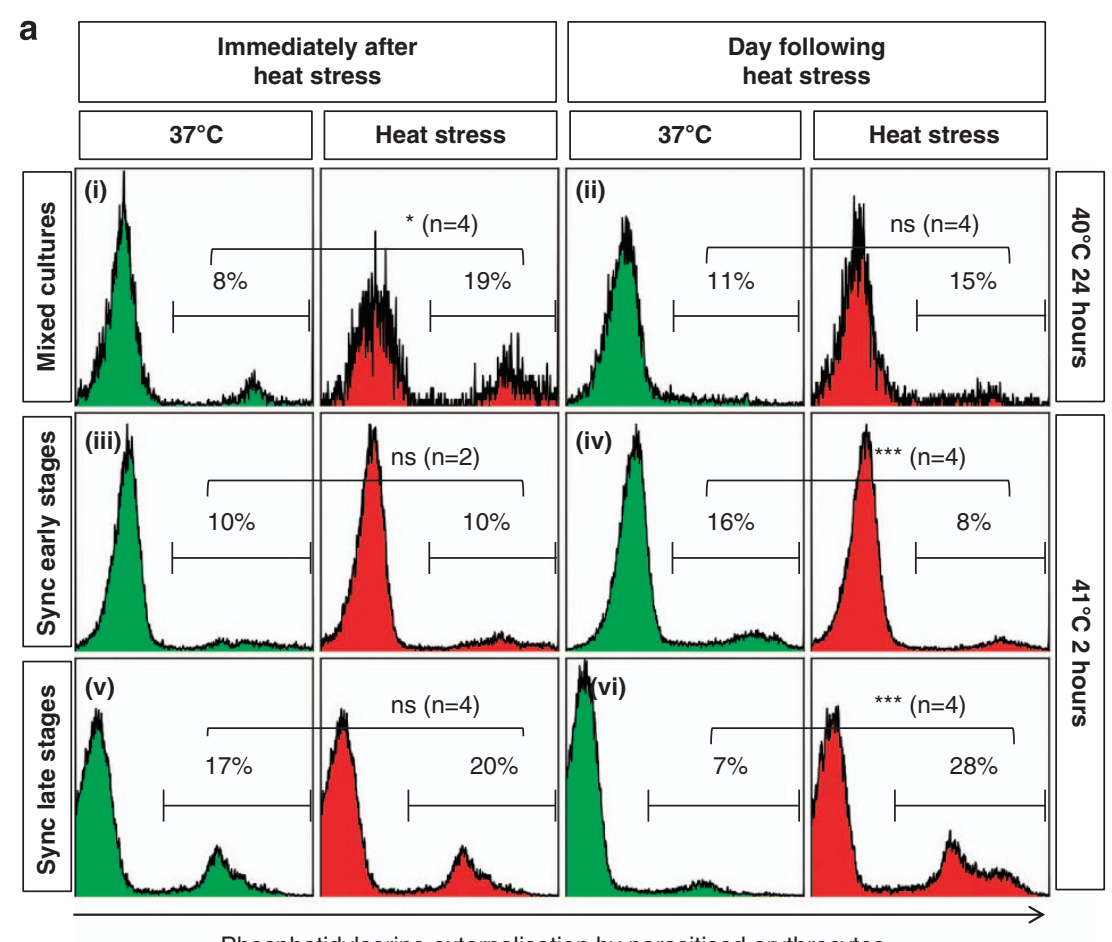

Phosphatidylserine externalisation by parasitised erythrocytes

$37^{\circ} \mathrm{C}$ Control $\square$ Heat stress
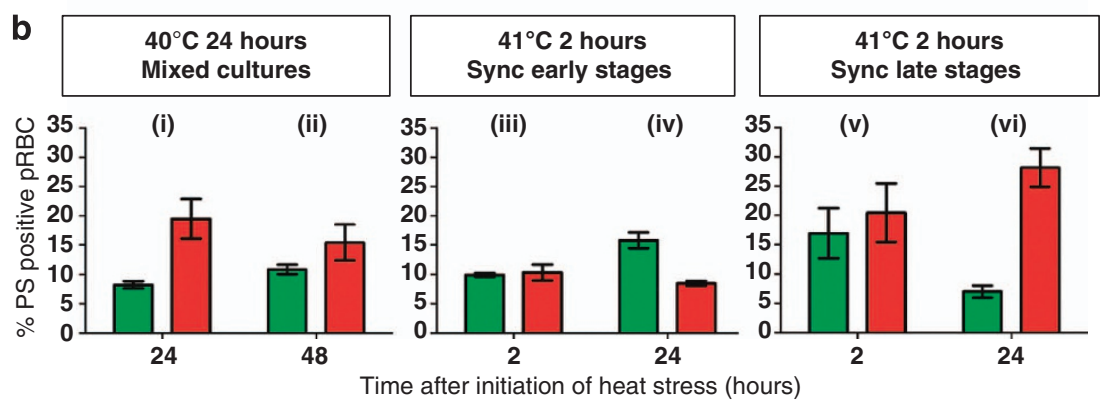

$\square 37^{\circ} \mathrm{C}$ Control $\square$ Heat stress

Figure 6 PS externalisation in pRBC exposed heat stress. (a) Fluorescence histograms and (b) bar graphs of pRBC showed an increase in PS externalisation by mixedstage cultures immediately after exposure to $40^{\circ} \mathrm{C}$ for $24 \mathrm{~h}$ (i) and was still apparent at $48 \mathrm{~h}$ (ii), although the latter difference was not statistically significant. No increase was noted in synchronised ring-stage pRBC immediately after exposure to $41^{\circ} \mathrm{C}$ for $2 \mathrm{~h}$ (iii), with an apparent decrease noted at $48 \mathrm{~h}$; however, it should be noted that the $37^{\circ} \mathrm{C}$ control parasites used for comparison had developed to late stages, which typically have higher PS externalisation, even without stress. When comparing the heat-stressed culture at both time points (iii and iv), no change was apparent. Although PS externalisation was not seen in late-stage pRBC exposed to $41^{\circ} \mathrm{C}$ for $2 \mathrm{~h}$ immediately after heat stress (v), an increase was observed a day later (vi). Representative histograms are merged data sets of at least two samples. Parasite stages are shown on the left as either mixed-stage cultures (Mixed) or synchronised (Sync) early- or late-stage cultures. Heat stress conditions are shown on the right. Gates on individual histograms indicate the percentage of infected erythrocytes that are PS positive. Comparisons between control and heat-stressed parasites have $P$-values that are significant at $<0.05$ ( $\left.^{*}\right),<0.001$ $\left({ }^{* * *}\right)$ or not significant (ns)

host? On the one hand, fever may provide the host with a mechanism for parasite clearance. ${ }^{5}$ Complete clearance would be most beneficial, but in this regard fever is relatively inefficient, as newly invaded parasites derived from the ruptured schizonts that caused the onset of fever are generally spared, even after high fever peaks. ${ }^{23}$ It seems likely that parasites that survived exposure to $40^{\circ} \mathrm{C}$ in this study were early-stage parasites. Our data showed that even after exposure to a high peak temperature of $41^{\circ} \mathrm{C}$, a significant number of ring-stage parasites and even some late-stage parasites survive, although a measurable increase in parasitaemia was only noted after several days of continuous culture. On the other hand, fever may provide a number of benefits to the parasite, including accelerated parasite maturation, as well as increased cytoadherence and reduced deformability of $\mathrm{PRBC}$, thought to aid in the sequestration of $\mathrm{pRBC}$ to microvasculature. ${ }^{9-12}$ With every asexual parasite capable of producing as many as 32 new merozoites at the end of a $48 \mathrm{~h}$ life cycle, ${ }^{24}$ uncontrolled parasite replication would place the host at risk of death before the slow-forming gametocytes could be transmitted. A potential mutual benefit of exposure to increased 

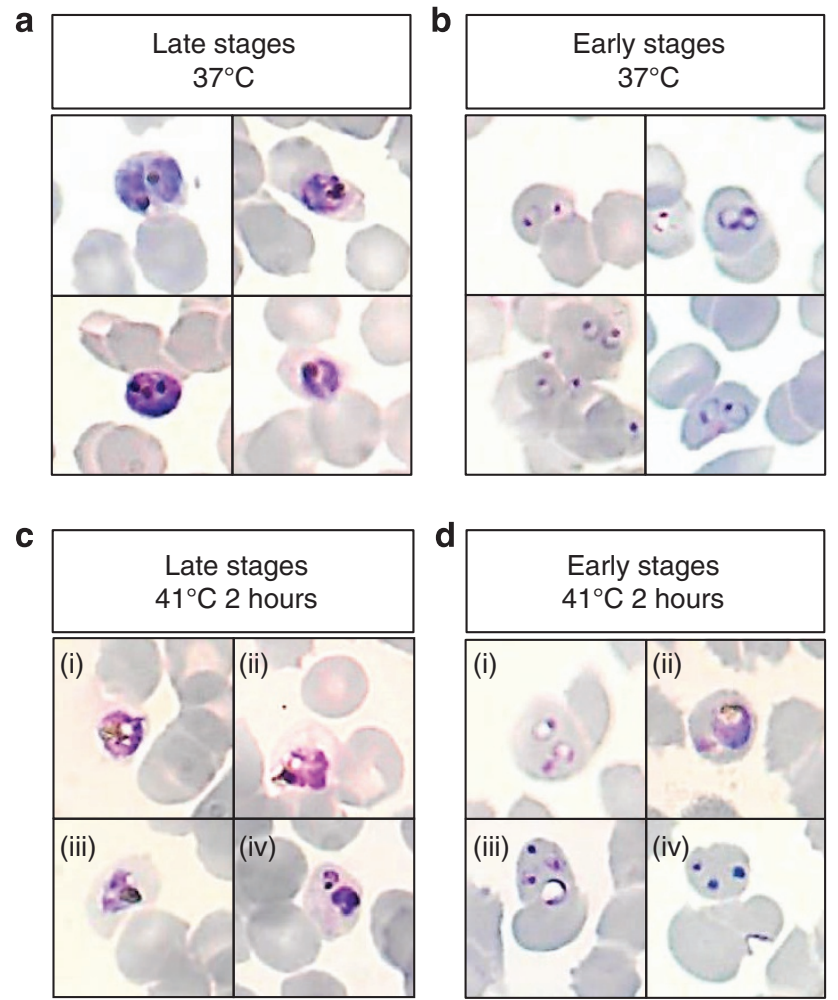

Figure 7 Heat stress induced abnormal morphology in $P$. falciparum. Control $P$. falciparum morphology showed trophozoites (a) that were large, full, well-rounded with clear and concentrated haemazoin and relatively even staining; and ring-stage parasites (b) that showed lightly-stained, delicate and rounded rings with single chromatin dots. In contrast, $24 \mathrm{~h}$ after exposure to $41^{\circ} \mathrm{C}$ for $2 \mathrm{~h}$, trophozoites (c) appeared unevenly stained with jagged borders and cytoplasmic vacuoles (ci-iii), or were condensed and very darkly stained (civ). Ring-stage parasites that were exposed to the same stress (d) showed variable morphology at $24 \mathrm{~h}$. Some rings appeared slightly vacuolised (di) and remained as ring-stage parasites $24 \mathrm{~h}$ after exposure instead of progressing to trophozoites. Some morphologically normal trophozoites were also observed (dii). Many ring-stage parasites were abnormally large with a central vacuole (diii). Chromatin-like dots without any ring structure were also observed in many cells (div)

temperatures therefore lies in the induction of PCD: by providing the parasite with the means to self-limitation, the burden of infection on the host is reduced, although sufficient parasites are conserved for continued sublethal infection. ${ }^{23,25}$ Our data suggest that intra-erythrocytic $P$. falciparum is likely to undergo PCD in response to heat stress.

PCD markers varied with life stages: different pieces, same puzzle? $P$. falciparum early and late developmental stages exhibited some intriguing differences in their response to the same stress conditions. Although ring-stage parasites exposed to $40^{\circ} \mathrm{C}$ for $24 \mathrm{~h}$ exhibited the depolarisation that is expected to result from the permeabilisation of the outer mitochondrial membrane during apoptosis, ${ }^{13}$ late-stage parasites exposed to the same stress surprisingly exhibited mitochondrial hyperpolarisation. Mitochondrial hyperpolarisation has been observed in protozoa other than Plasmodium. In heat-stressed Leishmania, hyperpolarisation formed an early part of an apoptosis-like cell death and was correlated with increased mitochondrial respiration, which drove superoxide radical production, in turn causing oxidative damage that mediated cell death. ${ }^{26}$ However, during apoptosis-like cell death in Trypansoma, mitochondrial hyperpolarisation was associated with decreased mitochondrial respiration. ${ }^{27}$ Both mitochondrial depolarisation and hyperpolarisation may be apoptosis responses in trypanosomatids. ${ }^{28}$ In metazoans, a transient increase in the $\Delta \Psi \mathrm{m}$ is thought to serve as a key checkpoint in determining cell fate, ${ }^{27}$ and is correlated with increased production and accumulation of reactive oxygen species (ROS) by the mitochondria during apoptosis. ${ }^{17,18}$ However, mitochondrial hyperpolarisation and increased ROS generation have also been implicated in the priming and occurrence of necrosis. ${ }^{15,29,30}$ In $P$. falciparum, we observed continued mitochondrial hyperpolarisation of late-stage parasites after $24 \mathrm{~h}$ exposure to $40^{\circ} \mathrm{C}$ and it is not entirely clear whether this marker is indicative of PCD or perhaps a necrosis-like form of cell death. Furthermore, the overall role of the mitochondrion in PCD in asexual $P$. falciparum may be questioned. Asexual stages of $P$. falciparum contain only a single, minimally active mitochondrion that functions primarily in de novo pyrimidine synthesis. ${ }^{31}$

We also observed differences between the PS externalisation of early- and late-stage pRBC exposed to $41^{\circ} \mathrm{C}$. In accordance with a previous study, ${ }^{10}$ late-stage pRBC showed increased PS externalisation after exposure to heat stress. However, no change was observed in early-stage pRBC. During apoptosis, loss of plasma membrane asymmetry results in PS externalisation, which is often used as a marker of apoptosis and is thought to serve as a signal in mammalian cells for phagocytes to engulf and digest cellular remnants. ${ }^{32}$ Would PS externalisation by pRBC be an advantage or disadvantage to the parasite residing within? Increased PS externalisation, observed both during parasite maturation ${ }^{10,33,34}$ and after stress by febrile temperatures, ${ }^{10}$ has been suggested to aid in the cytoadherence and sequestration of pRBC in microvasculature, thereby protecting parasites from splenic trapping and destruction. ${ }^{34,35}$ In this study, PS externalisation was only observed in late-stage pRBC exposed to $41^{\circ} \mathrm{C}$ a day after stress was withdrawn. PS externalisation also occurs during erythrocyte apoptosis, ${ }^{36,37}$ and oxidative stress from $P$. falciparum infection has been shown to induce host cell apoptosis ${ }^{38}$ and has been proposed to be the cause of PS externalisation in pRBC..$^{10}$ In this light, it is possible that increased PS externalisation by late-stage pRBC may simply be a by-product of oxidative stress from parasites.

Although biochemical markers of PCD are preferred over morphological criteria, ${ }^{15}$ the assessment of autophagy is largely based on morphology. ${ }^{39}$ Therefore, in light of the dissimilar responses of early- and late-stage parasites exposed to $41^{\circ} \mathrm{C}$, particularly the relative lack of biochemical markers of PCD exhibited by late-stage parasites despite a significant effect on parasite growth, morphological studies of both Giemsa-stained fixed slides and unstained, wet-mounted samples were also considered for parasites exposed to $41^{\circ} \mathrm{C}$.

Cytoplasmic vacuolisation was observed 1 day after heat stress for several subsequent days in late-stage parasites exposed to $41^{\circ} \mathrm{C}$ for $2 \mathrm{~h}$. Real-time microscopy showed that a 
significant number of late-stage parasites exposed to $41^{\circ} \mathrm{C}$ showed rapid movement within the food vacuole for several days after exposure to heat stress. Such movement is characteristic of healthy parasites ${ }^{21}$ and has been shown to be decreased by the antimalarial drug artesunate, which also caused the appearance of 'pyknotic' parasites. ${ }^{21,40}$ It has been suggested that loss of movement in the food vacuole is a very early indicator of an adverse parasite response to external stimuli that precedes other morphological changes. ${ }^{40}$ Despite showing a significant number of parasites that were apparently still alive, parasites did not form new ring-stage parasites as would be expected of healthy parasites (Figure 2) and the appearance of new ring-stage parasites and increasing parasitaemia was delayed by several days (Supplementary Figure 1). The eventual recovery of parasitaemia and the formation of new ring-stage parasites indicate that at least a few synchronised late-stage parasites survived exposure to $41^{\circ} \mathrm{C}$. The appearance of cytoplasmic vacuolisation, along with the lack of growth exhibited by apparently living parasites, is suggestive of an autophagy-like form of PCD. Similar to Totino et al., ${ }^{41}$ who observed autophagy-like cell death in drug-treated $P$. falciparum, we also observed very little DNA fragmentation by the TUNEL assay, which was deemed not to be significant. 'Crisis form' morphology was also reported by Oakley et al. ${ }^{7}$ under heat stress conditions similar to those employed by the present study.

Autophagy is a process of sequestration and subsequent degradation of cytoplasmic components that is regulated primarily by the sequential action of several autophagyrelated (Atg) proteins. Plasmodium genomes encode a number of putative Atg orthologues, ${ }^{42}$ although the most well-studied of these, the ubiquitin-like Atg8, has been shown to localise to the apicoplast, rather than the cytoplasm, in $P$. falciparum. ${ }^{43}$ Therefore, it is unclear whether the $P$. falciparum proteome encompasses the tools required to undergo autophagy-like cell death, with very few observations of the phenomenon reported. However, it has been suggested that the sequestration of micronemes and rhoptries in doublemembrane structures during the differentiation of sporozoites to trophozoites in hepatocytes may represent a type of functional autophagy in malaria parasites. ${ }^{42}$ It is also not clear whether autophagy 'in dying cells is the cause of death or actually an attempt to prevent it', ${ }^{39}$ particularly as autophagy often inhibits the induction of apoptosis or protects cells from exposure to apoptotic stimuli. ${ }^{44}$ Our own observations reflect this conflicting nature: the slow decrease of living parasites observed by real-time microscopy suggests that parasites are undergoing cell death; however, the eventual recovery of parasitaemia suggests that at least some parasites survive this process. It has been suggested that apoptosis and autophagy-like cell death are forms of PCD that may share some common regulatory proteins and the two may be induced simultaneously. ${ }^{44}$ We observed that the same stimulus that induced an apoptosis-like form of PCD in ringstage parasites also induced autophagy-like cell death in latestage parasites.

Apples and pears: the problem of identifying metazoan PCD phenotypes in $\boldsymbol{P}$. falciparum. Despite mounting evidence suggesting that $P$. falciparum undergoes PCD in response to heat stress, the exact phenotype of cell death remains undetermined. Apoptosis and autophagy are recognised phenotypes of $\mathrm{PCD}$, whereas necrosis is considered a non-PCD phenotype of cell death, ${ }^{15}$ although some active form of necrosis might also be possible. ${ }^{45}$ However, overlap between phenotypes may occur and many markers, including DNA fragmentation and mitochondrial depolarisation, may also occur during necrosis. ${ }^{14}$ Our data provided evidence suggesting that the asexual blood stages of $P$. falciparum may be capable of undergoing both apoptosis-like and autophagy-like forms of PCD. However, $P$. falciparum may exhibit a unique PCD phenotype that could include such phenomena as both mitochondrial hyperpolarisation and depolarisation-observations that were attributed to apoptosis in other protozoans. ${ }^{29}$ The origin of PCD may precede that of multicellularity ${ }^{46}$ and thus with an organism as phylogenetically ancient and evolutionary distant from other taxa as $P$. falciparum, ${ }^{47}$ attempting to impose metazoan PCD phenotypes may be misleading.

\section{Conclusion}

Intra-erythrocytic $P$. falciparum exhibited markers of an apoptosis-like PCD phenotype in ring-stage parasites and an autophagy-like cell death phenotype in late-stage parasites in response to heat stress. However, whether these are truly different phenotypes or simply different facets of a PCD phenotype unique to $P$. falciparum and distinct from metazoan apoptosis remains unclear. Elucidation of the underlying protein machinery responsible for the execution of PCD in $P$. falciparum will provide insight into the working of active cell death and the complex interactions between parasite and host.

\section{Materials and Methods}

Reagents. The APO-DIRECT TUNEL kit and FITC Annexin V Apoptosis Detection Kit II were obtained from Becton Dickinson (BD Pharmingen, San Diego, CA, USA). Thiazole orange (TO), HE, 3,3'-dihexyloxacarbocyanine iodide $\left(\mathrm{DiOC}_{6}(3)\right)$, carbonyl cyanide $m$-chlorophenylhydrazone (CCCP) were obtained from Sigma-Aldrich (St. Louis, MO, USA). Albumax II was obtained from Gibco (Gran Island, NY, USA).

P. falciparum culture. The 3D7 strain of $P$. falciparum was maintained according to established methods, ${ }^{48}$ with some modifications. ${ }^{49}$ Briefly, parasites were maintained in malaria culture medium (MCM: RPMI 1640, 0.5\% Albumax II and $0.21 \%$ sodium bicarbonate, supplemented with $50 \mathrm{mg} / \mathrm{l}$ gentamycin and $50 \mathrm{mg} / \mathrm{l}$ hypoxanthine) at $5 \%$ haematocrit in donor erythrocytes. MCM was changed daily. Optimal culture $\mathrm{pH}$ was maintained by daily gassing with a gas mixture of $2 \% \mathrm{O}_{2}, 5 \% \mathrm{CO}_{2}$ and $93 \% \mathrm{~N}_{2}$. Giemsa-stained smears were made daily to monitor parasite morphology. For studies involving synchronised cultures, parasite cultures were pelleted by centrifugation for $5 \mathrm{~min}$ at $1000 \times g$ and $25^{\circ} \mathrm{C}$ and the cell pellet incubated in $10 \mathrm{vol}$ of $5 \% \mathrm{D}$-sorbitol for $5-10 \mathrm{~min}$ at $37^{\circ} \mathrm{C}$. Centrifugation was repeated and the cell pellet was resuspended to $5 \%$ haematocrit with MCM and returned to culture. This method resulted in synchronisation of parasites at the ring stage, similar to previously described. ${ }^{50}$

Heat treatment. Parasitised erythrocytes were seeded as $5 \mathrm{ml}$ cultures at $1-5 \%$ parasitaemia in $25 \mathrm{~cm}^{3}$ flasks. Control parasite cultures were maintained at $37^{\circ} \mathrm{C}$. Mixed-stage cultures were exposed to $40^{\circ} \mathrm{C}$ for either 6 or $24 \mathrm{~h}$ and then maintained at $37^{\circ} \mathrm{C}$. Synchronised cultures were exposed to $41^{\circ} \mathrm{C}$ for $2 \mathrm{~h}$, and then maintained at $37^{\circ} \mathrm{C}$. Unless stated otherwise, samples for assays were collected immediately after heat stress as well as the following day. 
Flow cytometry. Flow cytometric analyses were performed on a Beckman Coulter Gallios flow cytometer (Beckman Coulter Inc., Miami, FL, USA). Excitation for all assays was by $488 \mathrm{~nm}$ blue laser. Emission was detected with the use of 545/40BP (525 $\pm 20 \mathrm{~nm}, \mathrm{FL} 1)$ and, where indicated, 575/30BP ( $575 \pm 15 \mathrm{~nm}, \mathrm{FL} 2)$ filters. Optical alignment was monitored daily with Beckman Coulter Flow Check Pro fluorospheres (Beckman Coulter Inc., Brea, CA, USA). Post-acquisition analyses were performed with Beckman Coulter Kaluza (v1.1) software.

TO flow cytometry for parasitaemia. Parasitaemia was measured daily by flow cytometry with the DNA-binding dye TO, similar to a previous method. ${ }^{51}$ Whole-culture samples $(10 \mu \mathrm{l})$ were diluted 100 -fold to $1 \mathrm{ml}$ in Sorenson's phosphate buffer ( $47 \mathrm{mM} \mathrm{Na}_{2} \mathrm{HPO}_{4}, 20 \mathrm{mM} \mathrm{KH}_{2} \mathrm{PO}_{4}, \mathrm{pH}$ 7.2) with $1 \mu \mathrm{M}$ TO final concentration (diluted from a $10 \mathrm{mM}$ stock in methanol) and incubated at room temperature in the dark for $20 \mathrm{~min}$. Stained cells were analysed by flow cytometry within $1 \mathrm{~h}$. Erythrocytes were gated on a forward- versus side-scatter dot plot and analysed on a FL1 integral (log) histogram, with regions for uninfected, ring-infected and trophozoite- or schizont-infected erythrocytes delineated. Approximately 50000 events in the erythrocyte gate were counted. Regions had previously been confirmed by microscopy of Giemsa-stained smears of synchronised cultures.

TUNEL assay for DNA fragmentation. The TUNEL assay was performed according to manufacturer's recommendations, with modifications similar to a previous study. ${ }^{7}$ Briefly, P. falciparum cultures were centrifuged and the cell pellets fixed on ice for $60-90 \mathrm{~min}$ in $4 \%$ formaldehyde and phosphate-buffered saline (PBS: $10 \mathrm{mM} \mathrm{Na}_{2} \mathrm{HPO}_{4}, 1.5 \mathrm{mM} \mathrm{KH}_{2} \mathrm{PO}_{4}, 137 \mathrm{mM} \mathrm{NaCl}, 2.7 \mathrm{mM} \mathrm{KCl}, \mathrm{pH} 7.4$ ), followed by permeabilisation with $0.1 \%$ tri-sodium citrate $(\mathrm{w} / \mathrm{v})$ and $0.1 \%$ Triton $\mathrm{X}-100$ (v/v) in PBS for $3 \mathrm{~min}$ on ice. Labelling with DNA-staining solution (including TdT enzyme and FITC-dUTP) was performed according to the manufacturer's recommendations for $60-90 \mathrm{~min}$ at $37^{\circ} \mathrm{C}$, followed by staining with propidium iodide (PI) for $30 \mathrm{~min}$ at room temperature. Labelled cells were analysed by flow cytometry within $3 \mathrm{~h}$. PI-positive parasites were acquired on a FL2 time-of-flight (lin) versus FL2 integral (lin) dot plot, with gated parasites analysed on a FL1 integral (log) histogram for DNA fragmentation, measured as FITC-dUTP fluorescence. At least $10000 \mathrm{PI}$ positive events were counted. DNase-treated, non-treated and unlabelled parasites were used as positive, negative and staining controls.

DiOC6(3) flow cytometry for $\Delta \Psi \mathbf{\Psi m}$. $P$. falciparum cultures were diluted 20 -fold in PBS, stained with $10 \mathrm{nM} \mathrm{DiOC}{ }_{6}(3)$ (diluted from a $100 \mathrm{mM}$ stock in DMSO) and $50 \mu \mathrm{M} \mathrm{HE}$ (diluted from a $10 \mathrm{mM}$ stock in DMSO) and incubated at $37^{\circ} \mathrm{C}$ for $45 \mathrm{~min}$ in the dark. Following incubation, cells were washed and suspended in $1 \mathrm{ml}$ PBS and analysed by flow cytometry immediately. Erythrocytes were gated on a forward- versus side-scatter dot blot. HE-positive pRBC counted on a FL2 integral (log) histogram were analysed for $\mathrm{DiOC}_{6}(3)$ fluorescence on a FL1 integral (log) histogram. At least 50000 events in the erythrocyte gate were counted. Positive controls were treated with $200 \mathrm{nM} \mathrm{CCCP} \mathrm{for} 1 \mathrm{~h}$ before staining. Unstained cells, cells stained with only $\mathrm{HE}$ or $\mathrm{DiOC}_{6}(3)$ and non-parasitised erythrocytes were used as staining controls. Mitochondrial depolarisation by the uncoupling agent carbonyl cyanide $m$-chlorophenyl hydrazone (CCCP, data not shown) confirmed the integrity of the assay.

Annexin V-FITC for PS externalisation. P. falciparum cultures were diluted 50-fold in PBS and stained sequentially with a final concentration of $50 \mu \mathrm{M}$ $\mathrm{HE}$ (diluted from a $10 \mathrm{mM}$ stock in DMSO) in PBS for $15 \mathrm{~min}$ at $37^{\circ} \mathrm{C}$ in the dark and annexin V-FITC in $1 \mathrm{X}$ annexin-binding buffer (provided with the kit), according to the manufacturer's recommendations with modifications similar to a previous study, ${ }^{10}$ for $15 \mathrm{~min}$ at room temperature in the dark. Stained cells were diluted to $1 \mathrm{ml}$ in $1 \mathrm{X}$ annexin-binding buffer and analysed by flow cytometry within $1 \mathrm{~h}$. Erythrocytes were gated on a forward- versus side-scatter dot blot and $\mathrm{pRBC}$ were discriminated on a FL 2 integral (log) histogram for HE fluorescence. Gated pRBC were analysed for annexin V-FITC fluorescence on a FL1 integral (log) histogram. At least 50000 events in the erythrocyte gate were counted. Parasitised cultures treated with recombinant annexin $V$ before staining were used as a negative control and unstained parasite cultures and parasite cultures stained with only $\mathrm{HE}$ or annexin V-FITC were used as staining controls.

Real-time microscopy. Samples of $41^{\circ} \mathrm{C}$ heat-stressed and $37^{\circ} \mathrm{C}$ control parasitised cultures were wet-mounted by placing $5 \mu$ l sample on a glass slide and covering the sample with a coverslip. Samples were observed with an Olympus
BX41 microscope under bright field and $\times 1000$ magnification with an immersion oil type objective lens, at room temperature, with a halogen light source. Real-time microscopy was performed immediately after heat stress and for 5 subsequent days. Live images were captured with an Olympus XC50 digital camera. Parasites observed with rapid movement within the food vacuole were considered to be alive. $^{21}$

Statistical analysis. Bar graphs were compiled using GraphPad Prism 5, with raw data values exported from analyses by Beckman Coulter Kaluza (v.1.1) software. Student's unpaired $t$-tests were performed with Microsoft Office Excel 2010 to test for significance between treated and control groups.

\section{Conflict of Interest}

The authors declare no conflict of interest.

Acknowledgements. We thank Professor Lesley E Scott and Beckman Coulter South Africa for the support provided in the use of the Beckman Coulter Gallios flow cytometer installed at the Department of Molecular Medicine and Haematology, University of the Witwatersrand and National Health Laboratory Service, Johannesburg, South Africa. We also thank Professor Robyn van Zyl of the Department of Pharmacy and Pharmacology, University of the Wiwatersrand, for the use of the Olympus BX41 fluorescence microscope. We further express our gratitude to Mr Warren A Vieira for invaluable observations and assistance with fluorescence microscopy as well as laboratory members of the Wits Research Institute for Malaria and Plasmodium Molecular Research Unit for helpful discussions. Funding was provided by the National Research Foundation (NRF) Grants 66072 and 73703, the University of the Witwatersrand and National Health Laboratory Service. Dewaldt Engelbrecht is funded by the National Research Foundation (NRF) Scarce Skills Scholarship-Grant no. 81556.

1. Miller LH, Good MF, Milon G. Malaria pathogenesis. Science 1994; 264: 1878-1883.

2. Miller LH, Baruch DI, Marsh K, Doumbo OK. The pathogenic basis of malaria. Nature 2002; 415: 673-679.

3. Longmore M, Wilkinson IB, Davidson EH, Foulkes A, Mafi AR. Oxford handbook of clinical medicine. Oxford University Press: New York, NY, USA, 2010. pp 394-397.

4. Kwiatkowski D. Febrile temperatures can synchronize the growth of Plasmodium falciparum in vitro. J Exp Med 1989; 169: 357-361.

5. Long HY, Lell B, Dietz K, Kremsner PG. Plasmodium falciparum: in vitro growth inhibition by febrile temperatures. Parasitol Res 2001; 87: 553-555.

6. Porter H, Gamette MJ, Cortes-Hernandez DG, Jensen JB. Asexual blood stages of Plasmodium falciparum exhibit signs of secondary necrosis, but not classical apoptosis after exposure to febrile temperature (40 C). J Parasitol 2008; 94: 473-480.

7. Oakley MSM, Kumar S, Anantharaman V, Zheng H, Mahajan B, Haynes JD et al. Molecular factors and biochemical pathways induced by febrile temperature in intraerythrocytic Plasmodium falciparum parasites. Infect Immun 2007; 75: 2012-2025.

8. Joshi B, Biswas S, Sharma YD. Effect of heat-shock on Plasmodium falciparum viability, growth and expression of the heat-shock protein 'PFHSP70-I' gene. FEBS Lett 1992; 312: 91-94.

9. Pavithra SR, Banumathy G, Joy O, Singh V, Tatu U. Recurrent fever promotes Plasmodium falciparum development in human erythrocytes. J Biol Chem 2004; 279: 46692-46699.

10. Pattanapanyasat $K$, Sratongno $P$, Chimma $P$, Chitjamnongchai S, Polsrila K, Chotivanich K. Febrile temperature but not proinflammatory cytokines promotes phosphatidylserine expression on Plasmodium falciparum malaria-infected red blood cells during parasite maturation. Cytometry A 2010; 77: 515-523.

11. Udomsangpetch R, Pipitaporn B, Silamut K, Pinches R, Kyes S, Looareesuwan S et al. Febrile temperatures induce cytoadherence of ring-stage Plasmodium falciparum-infected erythrocytes. Proc Natl Acad Sci USA 2002; 99: 11825-11829.

12. Marinkovic M, Diez-Silva M, Pantic I, Fredberg JJ, Suresh S, Butler JP. Febrile temperature leads to significant stiffening of Plasmodium falciparum parasitized erythrocytes. Am J Physiol Cell Physiol 2009; 296: C59-C64.

13. Pradelli LA, Bénéteau M, Ricci J-E. Mitochondrial control of caspase-dependent and -independent cell death. Cell Mol Life Sci 2010; 67: 1589-1597.

14. Engelbrecht D, Durand PM, Coetzer TL. On programmed cell death in Plasmodium falciparum: status quo. J Trop Med 2012; 2012: 1-15.

15. Kroemer G, Galluzzi L, Vandenabeele P, Abrams J, Alnemri ES, Baehrecke EH et al. Classification of cell death: recommendations of the Nomenclature Committee on Cell Death 2009. Cell Death Differ 2009; 16: 3-11.

16. Skulachev VP. Bioenergetic aspects of apoptosis, necrosis and mitoptosis. Apoptosis 2006; 11: 473-485. 
17. Banki K, Hutter E, Gonchoroff NJ, Perl A. Elevation of mitochondrial transmembrane potential and reactive oxygen intermediate levels are early events and occur independently from activation of caspases in Fas signaling. J Immunol 1999; 162: 1466-1479.

18. Joshi B, Li L, Taffe BG, Zhu Z, Wahl S, Tian H et al. Apoptosis induction by a novel anti-prostate cancer compound, BMD188 (a fatty acid-containing hydroxamic acid) requires the mitochondrial respiratory chain. Cancer Res 1999; 59: 4343-4355.

19. Sánchez-Alcázar JA, Ault JG, Khodjakov A, Schneider E. Increased mitochondrial cytochrome $c$ levels and mitochondrial hyperpolarization precede camptothecin-induced apoptosis in Jurkat cells. Cell Death Differ 2000; 7: 1090-1100.

20. Scarlett JL, Sheard PW, Hughes G, Ledgerwood EC, Ku HH, Murphy MP. Changes in mitochondrial membrane potential during staurosporine-induced apoptosis in Jurkat cells. FEBS Lett 2000; 475: 267-272.

21. Wongtanachai J, Silamut K, Day NPJ, Dondorp A, Chaisri U. Effects of antimalarial drugs on movement of Plasmodium falciparum. Southeast Asian J Trop Med Public Health 2012; 43: $1-9$

22. Gravenor MB, Kwiatkowski D. An analysis of the temperature effects of fever on the intra-host population dynamics of Plasmodium falciparum. Parasitology 1998; 117: 97-105.

23. Kwiatkowski D, Greenwood BM. Why is malaria fever periodic? A hypothesis. Parasitol Today 1989; 5: 264-266.

24. Bozdech Z, Llinás M, Pulliam BL, Wong ED, Zhu J, DeRisi JL. The transcriptome of the intraerythrocytic developmental cycle of Plasmodium falciparum. PLoS Biol 2003; 1: 85-100.

25. Deponte M, Becker K. Plasmodium falciparum-do killers commit suicide? Trends Parasitol 2004; 20: 165-169.

26. Alzate JF, Arias AA, Moreno-Mateos D, Álvarez-Barrientos A, Jiménez-Ruiz A Mitochondrial superoxide mediates heat-induced apoptotic-like death in Leishmania infantum. Mol Biochem Parasitol 2007: 152: 192-202.

27. Genes C, Baquero E, Echeverri F, Maya JD, Triana O. Mitochondrial dysfunction in Trypanosoma cruzi: the role of Serratia marcescens prodigiosin in the alternative treatment of Chagas disease. Parasit Vectors 2011; 4: 66.

28. Smirlis D, Duszenko M, Ruiz AJ, Scoulica E, Bastien P, Fasel N et al. Targeting essential pathways in trypanosomatids gives insights into protozoan mechanisms of cell death Parasit Vectors 2010; 3: 107.

29. Gergely P, Niland B, Gonchoroff N, Pullmann R, Phillips PE, Perl A. Persistent mitochondrial hyperpolarization, increased reactive oxygen intermediate production, and cytoplasmic alkalinization characterize altered IL-10 signaling in patients with systemic lupus erythematosus. J Immunol 2002; 169: 1092-1101.

30. Vanden Berghe T, Vanlangenakker N, Parthoens E, Deckers W, Devos M, Festjens N et al. Necroptosis, necrosis and secondary necrosis converge on similar cellular disintegration features. Cell Death Differ 2010; 17: 922-930.

31. Vaidya AB. The mitochondrion. In: Sherman IW (ed) Molecular Approaches to Malaria. ASM Press: Washington, DC, USA, 2005. pp 234-252.

32. Elmore S. Apoptosis: a review of programmed cell death. Toxicol Pathol. 2007; 35: 495-516.

33. Schwartz RS, Olson JA, Raventos-Suarez C, Yee M, Heath RH, Lubin B et al. Altered plasma membrane phospholipid organization in Plasmodium falciparum-infected human erythrocytes. Blood 1987; 69: 401-407.

34. Sherman IW, Eda S, Winograd E. Erythrocyte aging and malaria. Cell Mol Biol. 2004; 50 159-169.

35. Eda S, Sherman IW. Cytoadherence of malaria-infected red blood cells involves exposure of phosphatidylserine. Cell Physiol Biochem 2002; 12: 373-384
36. Lang KS, Duranton C, Poehlmann H, Myssina S, Bauer C, Lang F et al. Cation channels trigger apoptotic death of erythrocytes. Cell Death Differ 2003; 10: 249-256.

37. Lang PA, Kaiser S, Myssina S, Wieder T, Lang F, Huber SM. Role of Ca2 + -activated K + channels in human erythrocyte apoptosis. Am J Physiol Cell Physiol 2003; 285: C1553-C1560.

38. Lang F, Lang PA, Lang KS, Brand V, Tanneur V, Duranton C et al. Channel-induced apoptosis of infected host cells-the case of malaria. Pflugers Arch 2004; 448: 319-324.

39. Tsujimoto Y, Shimizu S. Another way to die: autophagic programmed cell death. Cell Death Differ 2005; 12(Suppl 2): 1528-1534.

40. Sachanonta N, Chotivanich K, Chaisri U, Turner GDH, Ferguson DJP, Day NPJ et al. Ultrastructural and real-time microscopic changes in $P$. falciparum-infected red blood cells following treatment with antimalarial drugs. Ultrastruct Pathol 2012; 35: 214-225.

41. Totino PRR, Daniel-Ribeiro CT, Corte-Real S, de Fátima Ferreira-da-Cruz M. Plasmodium falciparum: Erythrocytic stages die by autophagic-like cell death under drug pressure. Exp Parasitol 2008; 118: 478-486.

42. Brennand A, Gualdrón-López M, Coppens I, Rigden DJ, Ginger ML, Michels PAMM. Autophagy in parasitic protists: unique features and drug targets. Mol Biochem Parasitol 2011; 177: 83-99.

43. Kitamura K, Kishi-Itakura C, Tsuboi T, Sato S, Kita K, Ohta N et al. Autophagy-related Atg8 localizes to the apicoplast of the human malaria parasite Plasmodium falciparum. PloS One 2012; 7: e42977.

44. Thorburn A. Apoptosis and autophagy: regulatory connections between two supposedly different processes. Apoptosis 2008; 13: 1-9.

45. Galluzzi L, Kroemer G. Necroptosis: a specialized pathway of programmed necrosis. Cell 2008; 135: 1161-1163.

46. Ameisen JC. On the origin, evolution, and nature of programmed cell death: a timeline of four billion years. Cell Death Differ 2002; 9: 367-393.

47. Durand PM. On the molecular evolution of the Plasmodium falciparum genome: origin and evolution of a parasite's genome. VDM Academic Publishers: Saarbrucken, Germany, 2010.

48. Trager W, Jensen J. Human malaria parasites in continuous culture. Science 1976; 193: 673-675.

49. Mphande F, Nilsson S, Bolad A. Culturing of erythrocytic asexual stages of Plasmodium falciparum and $P$. vivax. In: Moll K, Ljungström I, Perlmann H, Scherf A, Wahlgren M (eds) Methods in Malaria Research. MR4/ATCC): Manassas, VA, USA, 2008. pp 1-3.

50. Lambros C, Vanderberg JP. Synchronization of Plasmodium falciparum erythrocytic stages in culture. J Parasitol 1979; 65: 418-420.

51. Schulze DLC, Makgatho EM, Coetzer TL, Louw Al, Van Rensburg CEJ, Visser L. Development and application of a modified flow cytometric procedure for rapid in vitro quantitation of malaria parasitaemia. S Afr J Sci 1997; 93: 156-158.

(c) (1) $\odot$ Cell Death and Disease is an open-access journal published by Nature Publishing Group. This work is licensed under a Creative Commons Attribution-NonCommercialNoDerivs 3.0 Unported License. To view a copy of this license, visit http://creativecommons.org/licenses/by-nc-nd/3.0/

Supplementary Information accompanies this paper on Cell Death and Disease website (http://www.nature.com/cddis) 